\title{
A Longer Running Internal Combustion Engine Using Simple Motif in Lubrication System Taking into Account Heat Reduction and Increased Performance
}

\author{
Dr. Mohammad M. Al-Azzawi ${ }^{1}$, MSc. Muayyad A.H Al-Hayali ${ }^{2}$ and MSc. Kousay N. Al-Ane ${ }^{3}$ \\ ${ }^{1}$ Professor \& Head and ${ }^{2,3}$ University Professor \\ Department of Air-Conditioning Engineering \\ Al-Rafidain University College \\ Baghdad, Iraq
}

ABSTRACT

Most important aspect of machine and auto life would be the proper lubrication, well-oiled automobile will outlast maintained poorly models by many years. No different when it comes to Industrial machinery, save a lot of money and hassle in the future if a good lubrication system is introduced [1]. Moving machine parts are accomplished by lubricating systems which introduce oil, grease and other lubricants to them. Reduced friction between parts by means of lubricants, Longevity is increased [1]. Without lubrication, most machines would overheat or suffer extreme damage [2]. Anyone who has ever neglected to keep their car oiled knows first-hand just how extensive this damage can be. Cooling and lubricating systems are the fundamentals part of almost all internal combustion engines that work in conjunction with each other promoting sustainable engine performance. Hence, lubricating systems are integral part of any engine system that contribute in heat reduction during operation, less heat guarantees longer life engine components. In this research a simple motif in lubrication system will make significant improvement in i.c. engine system.

Key Words: Lubricating Systems, Internal Combustion Engines (I.C. Engines), Engine Components.

\section{INTRODUCTION}

There are differences in the application of features of their cooling and lubricating systems, keeping in mind that their maintenance procedures and operational characteristics vary through engines, I.C. engines equipped with an internal lubricating system, an engine quickly overheats due to any lack in lubrication and excessive friction will occur [1,4]. All moving parts must be adequately lubricated to assure long engine life, the main lubrication purpose is to reduce friction and wear between moving parts also inside engine cleaning by removing contaminants (metal, dirt, plastic, rubber, and other particles) and quite engine operation by absorbing shocks between moving parts, in this research a simple plated heat exchanger is applied inside the I.C. engine pan to lower down as much heat as possible then the coolant with pass through it on the way to the radiator again completing cycle done by the engine cooling system $[2,3]$.

\section{LUBRICATING SYSTEM IN I.C. ENGINE}

Lubricating system is a necessary part of the engine and the operation of one depends upon the operation of the other, thus the lubricating system basically consists of the following.

\subsection{OIL PUMP}

The oil pump in figure [1] considered the lubricating system heart; it forces oil out of the oil pan, through the oil filter and galleries, and to the engine bearings. Usually, a gear on the engine camshaft drives the oil pump; however, a cogged belt or a direct connection with the end of the camshaft or crankshaft drives the pump. 


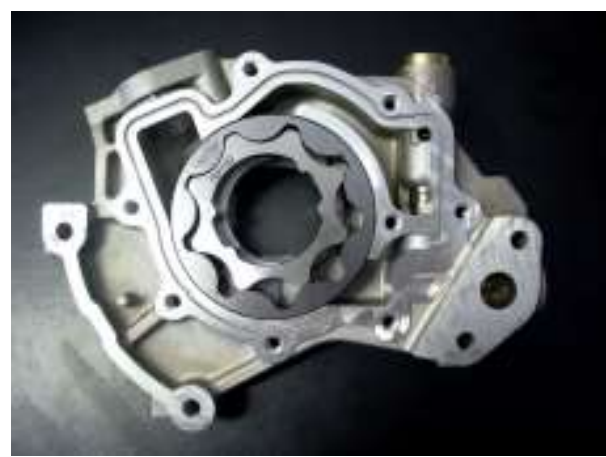

Figure 1: Oil Pump

\subsection{OIL PICKUP AND STRAINER}

Tube that extends from the oil pump to the bottom of the oil pan. One end to the engine block or at the pickup tube bolts or screws into the oil pump. Straining large particles from the oil due to the strainer job that has a mesh screen suitable and yet passes a sufficient quantity of oil to the inlet side of the oil pump, strainer is located so that all oil entering the pump from the oil pan must flow through it. Some assemblies also incorporate a safety valve that opens in the event the strainers become clogged, thus bypassing oil to the pump. Figure [2]
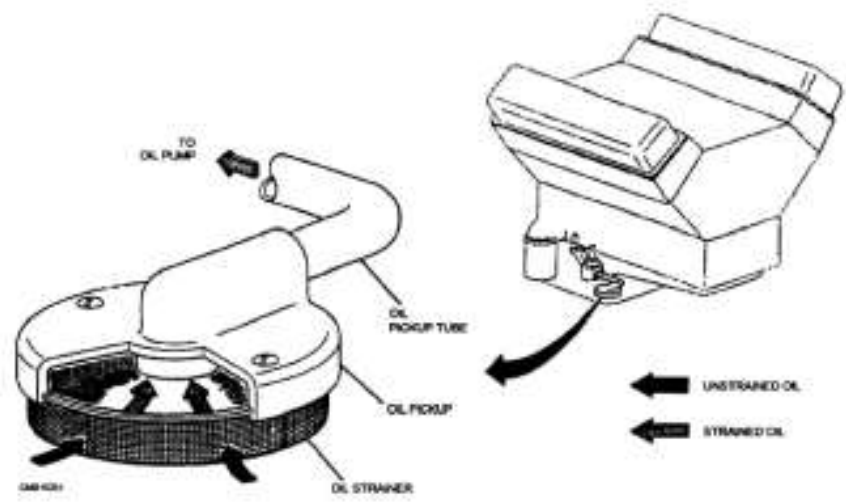

Figure 2: Oil Pickup and Strainer

\subsection{PRESSURE RELIEF VALVE}

The pressure relief valve is a spring-loaded bypass valve in the oil pump, engine block, or oil filter housing. The valve consists of a small piston, spring, and cylinder. Under normal pressure conditions, the spring holds the relief valve closed. All the oil from the oil pump flows into the oil galleries and to the bearings.

\subsection{OIL FILTER}

Impurities that have been picked up by the oil would be removed by oil filter as it circulates through the engine. Designed to be replaced readily, the filter is mounted in an accessible location outside the engine. Figure [3]

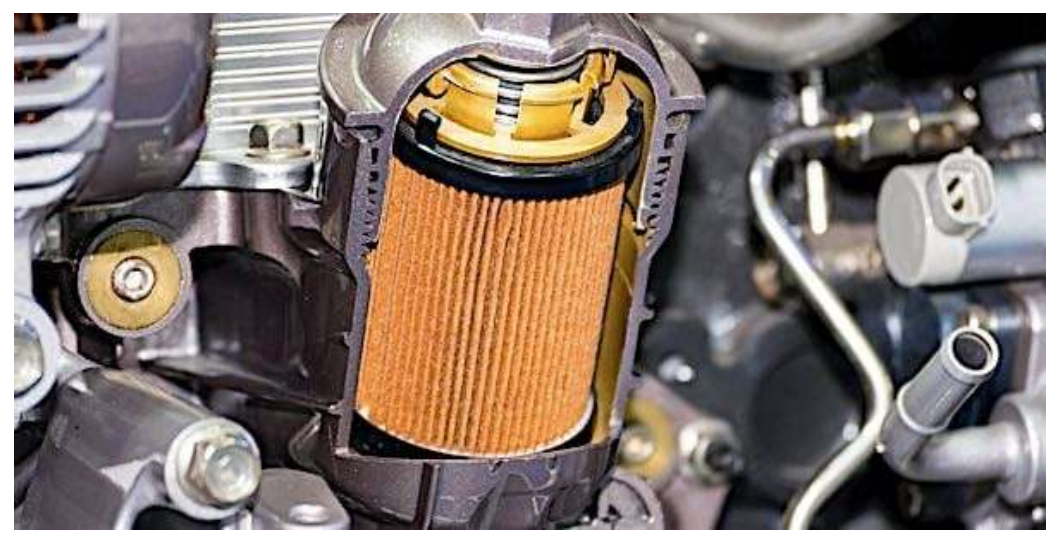

Figure 3: Oil Filter [Type: Cartridge] 


\subsection{OIL PAN}

Thin sheet metal or aluminum normally made to form the oil pan, and bolts to the bottom of the engine block. It holds a supply of oil for the lubrication system. The oil pan is fitted with a screw-in drain plug for oil changes. Keeping the oil from splashing around in the pan is the main duties of baffles. The lowest area which is called the sump in the oil pan where oil collected. As oil drains from the engine, it fills the sump. Then the oil pump can pull oil out of the pan for recirculation.

\subsection{OIL LEVEL GAUGE}

Usually the bayonet type illustrated in (Figure 6-22). It contain a long rod or blade that extends into the oil pan. To show the level of oil within the oil pan a marking is necessary. By pulling the rod out from its normal place in the crankcase the readings are made. It is mandatory part that the oil level never drop below the low mark or rise above the full mark to make sure that the oil is in the normal ratio.

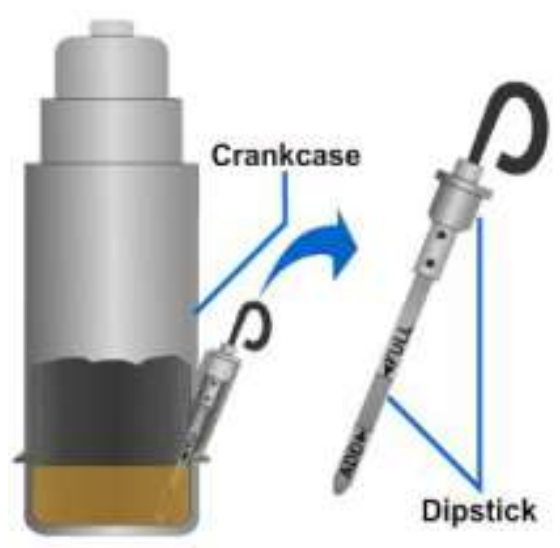

Figure 4: Oil Level Gauge

\subsection{OIL VESTIBULE}

Small passages through the cylinder block and head for lubricating oil. They are cast or machined passages that allow oil to flow to the engine bearings and other moving parts. The main oil vestibule are large passages through the center of the block. crankshaft bearings are feed by them also camshaft bearings, and lifters. The main oil vestibule also feed oil to smaller passages running up to the cylinder heads.

\subsection{OIL PRESSURE WARNING LIGHT}

Many vehicles use the pressure warning light, a low oil pressure condition is valuable to notice, because the engine can fail or be damaged in less than a minute of operation without oil pressure, the caution of warning light is used as a backup for a gauge to attract instant attention to a malfunction. Ignition switch fed the power to the oil pressure warning light. The circuit to ground is completed through the oil pressure-sending unit that screws into the engine and is exposed to one of the oil vestibules. The sending unit consists of a pressure sensitive diaphragm that operates a set of contact points. Approximately 15 psi in most vehicles are calibrated to turn on the warning light anytime oil pressure drops below that psi.

\subsection{OIL PRESSURE GAUGE}

Usually placed on the instrument panel of a vehicle. Marked off on a dial in pounds per square inch (psi), How regularly and evenly the oil is being delivered to all vital parts of the engine are the main purpose of the gauge indication and warns of any stoppages in this delivery. It can be mechanical or electrical. The gauge on the instrument panel is connected to an oil line tapped into an oil vestibules leading from the pump, the pressure of the oil in the system acts on a diaphragm within the gauge, causing the needle to register on the dial, this would be the typical mechanical type. In the electrical type on the other hand, oil pressure operates a rheostat connected to the engine that signals electrically to the pressure gauge indicating oil pressure within the system.

\subsection{OIL TEMPERATURE REGULATOR}

Usually used in diesel engine lubricating systems. In hot weather it preventing oil temperature from rising too high, while assist it during winter by raising the temperature. It provides a more positive means of controlling oil temperature than does cooling by radiation of heat from the oil pan wells. The regulator uses engine coolant in the cooling system to regulate the temperature of the oil and is made up of a core and housing. The core, through which the oil circulates, is of cellular or bellows construction and is built to expose as much oil as possible to the coolant that circulates through the housing. The regulator is attached to the engine so 
that the oil will flow through the regulator after passing through the pump. As the oil passes through the regulator, it is either cooled or heated, depending on the temperature of the coolant, and then is circulated through the engine.

\section{PROPOSED COOLING SYSTEM IN LUBRICANT DESIGN}

Image illustrate in Figure [5] introduces the proposed cooling mechanism and how the added plated heat exchanger in the pan of I.C. Engine can contribute in heat reduction however much more benefits will became handy if we consider less heat can be the rule of thumb to longer operation periods

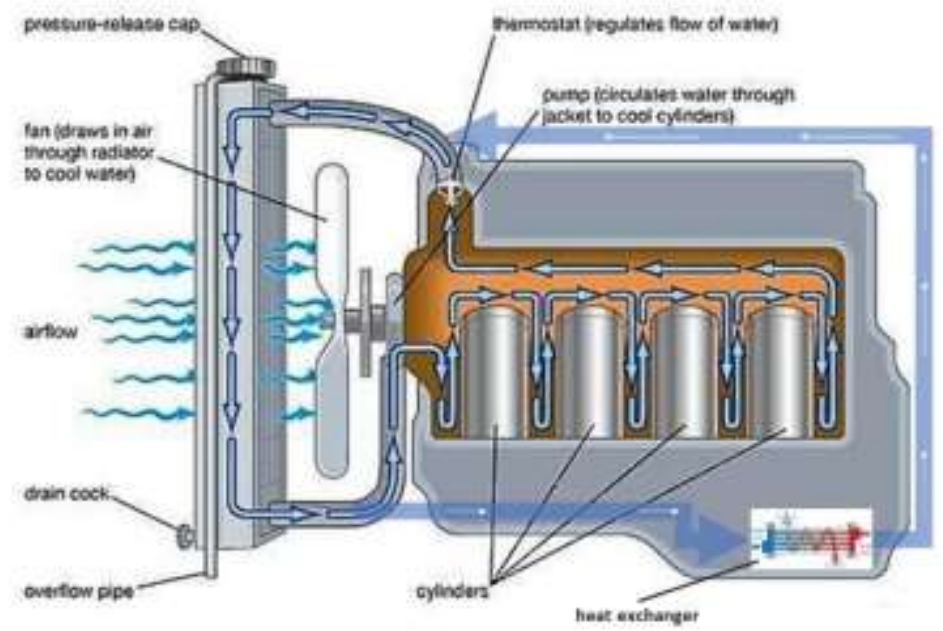

Figure 5: Proposed Cooling Lubricant System Design

\section{CONCLUSION}

Cooling and lubricating systems are the fundamentals part of almost all internal combustion engines so it's a vital part that shouldn't be ignored the proposed system when adding the plated heat exchanger, it Can contribute in heat reduction and longer operation hours and improving life span for i.c. engine components.

\section{REFERENCES}

[1] https://www.thomasnet.com/about/lubricating-systems-45021003.html

[2] Power plant handbook, chapter six: cooling and lubrication systems

[3] Schultheiss, Hansjoerg \& Tobie, Thomas \& Stahl, Karsten. (2015). The Effect of Selected Grease Components on the Wear Behavior of Grease-Lubricated Gears. Journal of Tribology. 138. 10.1115/1.4031278.

[4] Bansal, Vipan. (2015). Effect of Cutting Parameter on Hard Turning by Using Different Lubricating Conditions: A Review. International Journal of Engineering Trends and Technology. 30. 75-82. 10.14445/22315381/IJETT-V30P215. 